\title{
Differentiation of Polyamide 6, 6.6, and 12 Contaminations in Polyolefin-Recyclates Using HPLC Coupled to Drift-Tube Ion-Mobility Quadrupole Time-of-Flight Mass Spectrometry
}

\author{
Andrea Schweighuber ${ }^{1, *}$, Jörg Fischer ${ }^{2}\left(\mathbb{D}\right.$ and Wolfgang Buchberger ${ }^{1} \mathbb{D}$ \\ 1 Institute of Analytical Chemistry, Johannes Kepler University, Altenbergerstraße 69, 4040 Linz, Austria; \\ wolfgang.buchberger@jku.at \\ 2 Institute of Polymeric Materials and Testing, Johannes Kepler University, Altenbergerstraße 69, \\ 4040 Linz, Austria; joerg.fischer@jku.at \\ * Correspondence: andrea.schweighuber@jku.at
}

check for updates

Citation: Schweighuber, A.; Fischer, J.; Buchberger, W. Differentiation of

Polyamide 6, 6.6, and 12

Contaminations in Polyolefin-

Recyclates Using HPLC Coupled to Drift-Tube Ion-Mobility Quadrupole Time-of-Flight Mass Spectrometry. Polymers 2021, 13, 2032. https:// doi.org/10.3390/polym13122032

Academic Editor: Krzysztof Formela

Received: 1 June 2021

Accepted: 17 June 2021

Published: 21 June 2021

Publisher's Note: MDPI stays neutral with regard to jurisdictional claims in published maps and institutional affiliations.

Copyright: (c) 2021 by the authors. Licensee MDPI, Basel, Switzerland. This article is an open access article distributed under the terms and conditions of the Creative Commons Attribution (CC BY) license (https:/ / creativecommons.org/licenses/by/ $4.0 /)$.

\begin{abstract}
Recycling is a current hot topic with a focus especially on plastics. The quality of such plastic recyclates is of utmost importance for further processing because impurities lead to a reduction thereof. Contaminations originating from other polymers are highly problematic due to their immiscibility with the recyclate, leading to possible product failures. Therefore, methods for the determination of polymer impurities in recyclates should be investigated. In this paper, an approach for the identification of three different polyamide grades (polyamide 6, 6.6, and 12) is presented, applicable for the analysis of polyolefin-recyclates. An HPLC equipped with a drift-tube ion-mobility QTOF-MS was used for the identification and differentiation of compounds originating from the polyamides, which were then used as markers. These marker compounds are specific for each type and can be identified by their corresponding value of the collision cross section (CCS). After a simple sample preparation, all three types of polyamides were identified within one measurement. In particular, the problematic differentiation of polyamide 6 and 6.6 was easily made possible.
\end{abstract}

Keywords: recyclates; polyamide; contaminations; liquid chromatography; ion mobility

\section{Introduction}

Worldwide major objectives are required to be set in order to manage the increasing amount of waste generated every day. In the European Union (EU) alone, 2327 million tons of waste were generated by the industry and households in 2018 [1]. These huge amounts need to be reasonably reused in order to conserve scarce resources. A focus was set on the implementation of a circular economy by life cycle assessments and waste management strategies. The EU positioned itself as a pioneer by enforcing programs and directives, such as the Environment Action Programme, having the main goals of waste reduction, recycling, and limitation of incineration and landfill of waste [2]. A differentiation of these wastes and waste streams is necessary, due to the different encountered challenges. Recently, a focus on plastic waste and the handling thereof was initiated. The Directive (EU) 2018/852 specifically targets minimum recycling quotas for plastic waste of $50 \%$ by 2025 and of $55 \%$ by 2030 , respectively [3].

Different sources of plastic waste can facilitate or complicate further processing. Waste streams originating from the primary production of plastics can easily be recycled due to the purity of the polymer. Plastics deriving from municipal waste possess a more complex and heterogeneous composition, and hence a crucial component of mechanical recycling is proper sorting to generate pure streams. Solely homogeneous recyclates are suitable for the production of valuable products and for representing a real alternative to virgin materials [4,5]. In 2018, 29.1 Mt of post-consumer plastic waste was collected in the EU, whereby $32.5 \%$ was recycled $(42.6 \%$ was used for energy recovery and $24.9 \%$ was 
landfilled). Approximately 17.8 Mt of this waste consisted of post-consumer packaging waste, reaching a recycling rate of $42 \%$ (39.5\% was used for energy recovery and $18.5 \%$ was landfilled).

The most prominent polymers in packaging applications are polyolefins, namely high- and low-density polyethylene and polypropylene [6]. Polymer contaminations in polyolefin-recyclates can be problematic due to the immiscibility of different polymer mixtures, and these inhomogeneities can lead to a reduction of mechanical properties and thus to eventual product failures [4,7-10]. Therefore, it is important to acquire a general understanding of the composition of municipal plastic wastes through the analysis of the origin of polymer contaminations [11,12]. Such impurities often derive from composite materials consisting of more than one polymer type, for example, multilayer films used in the food packaging industries. [13,14] Polyamides (PA) are used excessively: 41\% of simple multilayer films consist of polyolefin/polyamide blends and a share of $30 \%$ is reached with regard to thermoformed packaging films [15].

Polyamides have several advantages dependent on the type of PA. Polyamide 6, polymerized using $\varepsilon$-caprolactam, offers great long-term heat resistance, polyamide 6.6, produced from 1,6-hexamethylenediamine and adipic acid, has excellent gas barrier properties, and polyamide 12, synthesized with aminolauric acid or dodecalactam, possesses the lowest water absorption of all polyamide grades [16-18].

PA is one of the major polymer contaminants in polyolefin-recyclates and methods for the analysis of low amounts of PA should be developed in order to provide essential information on recyclate quality. Generally, quality control measurements of recyclates are often performed using differential scanning calorimetry (DSC), thermogravimetric analysis (TGA), melt-flow index (MFI), or Fourier-transform infrared (FTIR)-spectroscopy. DSC and TGA can first be approached for a statement about the purity of the polymer, yet a clear differentiation of the contamination is difficult, especially with regard to different types of polyamides [5,19]. Pure polyamides are often characterized by IR spectroscopy, yet due to the low concentration in polyolefin-recyclates, interfering signals of additives containing amide groups complicate this analysis technique. Similarly, another technique applicable is DSC, whereby polyamides can be distinguished, but again, low concentrations pose a problem $[20,21]$. For waste materials containing high amounts of polyamides $(>60 \%)$, Zagar et al. developed a method for the analysis of PA 6 and 6.6 by a total hydrolysis of the polymer to small linear species, followed by an HPLC-MS method for the quantification [22]. However, this method is not applicable for the determination of PA contaminations in polyolefin-recyclates because of possible incomplete hydrolysis of the polyamides due to the polyolefin matrix and the low amount of polyamide present in these recyclates.

Therefore, alternative methods for the analysis of low contents of polyamides need to be established for recyclates. An attractive new strategy can be based on targeting not the polymer itself, but low-molecular-mass linear or cyclic oligomers existing in PA and serving as markers for the presence of PA in recyclate materials. Methods for the analysis of such oligomers already exist in the context of risk assessments of PA food contact materials using migration experiments [23-30]. To date, this approach has also been applied to polyolefin-recyclates containing polyamide 6 , and included an extraction of the cyclic oligomers followed by HPLC-MS analysis [31]. Yet, to evaluate which types of polyamides are present and to later generate a sum parameter of total polyamide contaminations, this method has limitations. In particular, the differentiation of polyamides with the focus on the three predominant grades PA 6, PA 6.6, and PA 12 has not yet been achieved. Dependent on the type of polyamide, different analytes suitable as marker substances should be further investigated. A predominant problem is the differentiation of these markers due to their similarities in structure, exact mass, and retention time. Especially if a combination of polyamide grades is present in a recyclate, a differentiation by HPLC-MS is not possible. Therefore, an additional level of separation needs to be introduced by usage of a drift-tube ion-mobility mass spectrometer. Through the different shapes of the molecules, differences in the spherical size in the gas phase exist. This fact can then be used in the drift-tube to 
separate molecules even when they have the same exact mass and retention time. The resulting collision cross section is a unique parameter for each marker compound, which can be calculated by the individual drift times of the molecules.

Therefore, the aim of this work is the differentiation of polyamides using an HPLC coupled to a drift-tube ion-mobility quadrupole/time-of-flight mass spectrometer (DTIM-QTOF-MS), later applicable for polyolefin recyclates. This research helps to develop a better understanding of the origin of polyamide contaminations in different waste streams, leading to possible improvements in recycling by reduction of these impurities.

\section{Materials and Methods}

\subsection{Chemicals}

All chemicals used were of analytical grade. The extraction solvents methanol and toluene were purchased from VWR International GmbH (Darmstadt, Germany). Highpurity water $(18 \mathrm{M} \Omega \mathrm{cm})$ generated from a Millipore purification system (Molsheim, France), acetonitrile and formic acid ( $>99 \%$ ) from VWR International GmbH (Darmstadt, Germany), and ammonium formate (97\%) purchased from Sigma Aldrich Handels GmbH (Vienna, Austria) were used for the mobile phases. The analyzed polyamide 6, 6.6 and 12 samples were commercially available from local manufacturers.

\subsection{Instrumentation}

Method development and qualitative analysis were performed on an Agilent 1260 HPLC system, comprising a 1260 flexible pump, a $1290 \mathrm{MCT}$, and a 1260 autosampler (Agilent Technologies, Santa Clara, CA, USA) coupled to a 6560 DTIM QTOF-MS equipped with a Dual Agilent Jet Stream Electrospray Ionization (Dual AJS-ESI) source and a gas kit (Alternate Gas Kit, Agilent Technologies, Santa Clara, CA, USA). A gradient elution was performed using an XBridge BEH Amide HILIC column $(2.1 \mathrm{~mm} \times 100 \mathrm{~mm}$, $2.5 \mu \mathrm{m}$; Waters, Milford, MA, USA) equipped with an XBridge Glycan BEH Amide guard column $(2.1 \mathrm{~mm} \times 5 \mathrm{~mm}, 2.5 \mu \mathrm{m}$; Waters, Milford, MA, USA). A mobile phase flow of $0.3 \mathrm{~mL} \mathrm{~min}{ }^{-1}$ was employed and the column was maintained at $30^{\circ} \mathrm{C}$. Injection volume was $2 \mu \mathrm{L}$.

The optimized mobile phase consisted of $5 \mathrm{mM}$ ammonium formate in water containing $0.1 \%$ formic acid (A), acetonitrile with $0.1 \%$ formic acid (B), and $100 \mathrm{mM}$ ammonium formate in water containing $0.1 \%$ formic acid (C). The gradient elution was performed as follows: starting with $15 \% \mathrm{~A}$ and $85 \% \mathrm{~B}$, held for two minutes, followed by a linear increase to $15 \% \mathrm{~A}, 55 \% \mathrm{~B}$, and $30 \% \mathrm{C}$ from minutes 2 to 8 , and held constant for $4 \mathrm{~min}$. The gradient was changed to the starting conditions within $0.5 \mathrm{~min}$ and held for $7.5 \mathrm{~min}$ for re-equilibrating the column.

The ESI source was operated in the positive mode. As sheath and drying gas, nitrogen, was used. Sheath gas temperature was set to $350{ }^{\circ} \mathrm{C}$ at a flow rate of $11 \mathrm{~L} \mathrm{~min}^{-1}$. The temperature of the drying gas was $250{ }^{\circ} \mathrm{C}$ using a flow of $10 \mathrm{~L} \mathrm{~min}^{-1}$. The nebulizer pressure was set to $35 \mathrm{psi}$, the fragmentor voltage to $400 \mathrm{~V}$, the capillary voltage to $3500 \mathrm{~V}$, and the nozzle voltage to $1000 \mathrm{~V}$. An auto-tune in the 2-GHz extended dynamic range setting in the $1700 \mathrm{~m} / \mathrm{z}$ mode was performed. A 4-bit pulsed multiplexing was applied, using a trap fill time of $3900 \mu \mathrm{s}$ and a trap release time of $250 \mu \mathrm{s}$. The frame rate was set to 0.9 frames s$~^{-1}$, the IM transient rate was 18 transients frame ${ }^{-1}$ and the maximum drift time was $60 \mathrm{~ms}$. For the calculations of the collision cross section $\left({ }^{\mathrm{DT}} \mathrm{CCS}_{\mathrm{N} 2}\right)$ using a drift-tube (DT) and nitrogen as collision gas, a single field calibration was performed using an Agilent tuning mix. The applied IM parameters for the DT measurements were in accordance with [32]: $1574 \mathrm{~V}$ drift-tube entrance voltage, $224 \mathrm{~V}$ drift-tube exit voltage, $217.5 \mathrm{~V}$ rear funnel entrance voltage and $45 \mathrm{~V}$ rear funnel exit voltage.

\subsection{Sample Preparation}

A microwave-assisted extraction was performed using $100 \mathrm{mg}$ sample and $2 \mathrm{~mL}$ solvent (methanol/toluene, 50/50) in G4 reaction vessels (Anton Paar GmbH, Graz, Austria). 
The microwave was a Monowave Extra equipped with a MAS24 autosampler (Anton Paar GmbH, Graz, Austria). The following parameters for the extraction were applied: a constant temperature of $160{ }^{\circ} \mathrm{C}$ was held for $20 \mathrm{~min}$ with stirring at a speed of $600 \mathrm{rpm}$, followed by a cooling step to $40^{\circ} \mathrm{C}$. The samples were then further filtrated in HPLC glass vials using Chromafil AO-45/25 RC filters (Macherey Nagel, Düren, Germany). A solvent change to acetonitrile was done by the evaporation of $500 \mu \mathrm{L}$ of each sample to dryness under a nitrogen stream and reconstitution with $500 \mu \mathrm{L}$ acetonitrile. Prior to the analysis, the samples were diluted by a factor of 10 if the concentration exceeded $10 \mathrm{wt} \%$ of polyamide content in a recyclate.

\subsection{Data Evaluation}

The Agilent MassHunter LCMS Acquisition software 10.0 was used for the data acquisition. The multiplexed data were then further processed with the PNNL PreProcessor 3.0 software for de-multiplexing the data. IM data was first calibrated with the single field tune using the IM-MS Browser software. The determination of the ${ }^{\mathrm{DT}} \mathrm{CCS}_{\mathrm{N} 2}$ values was conducted using the feature extraction (IMFE) in the IM-MS Browser with the following settings: Chromatographic processing of "common organic molecules" with a limited charge state of $z \leq 2$. The ion intensity was set to $\geq 100$ and the retention time was restricted to $1-4 \mathrm{~min}$.

The software Agilent MassHunter Qualitative Analysis B.10.00 and Agilent IM-MS Browser 10.0 were employed for data evaluation.

\section{Results and Discussion}

The first step towards a qualitative method for the analysis of polyamides was the identification of relevant marker molecules, which are representative for the different types of polyamides. Therefore, the samples were prepared by using an optimized extraction procedure and analyzed by HPLC-QTOF-MS using a HILIC column as was previously done for PA 6 [31], where cyclic compounds related to $\varepsilon$-caprolactam were identified. As shown in Figure 1, similar cyclic compounds can be expected for PA 6.6 and PA 12 due to their similar chemical structures by the polymerization reaction for these three types of PA. Polyamide 6 and 6.6 only vary in the location of the functional groups. Polyamide 6 is polymerized using $\varepsilon$-caprolactam (a), polyamide 6.6 is produced from 1,6-hexamethylenediamine and adipic acid (b), and polyamide 12 is synthesized with aminolauric acid or dodecalactam (c).

(a)

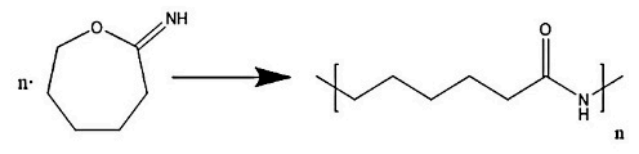

(b)

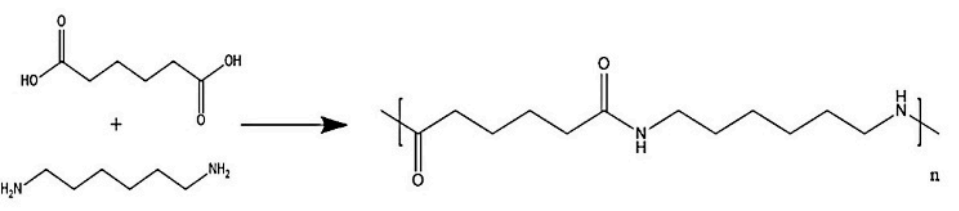

(c)

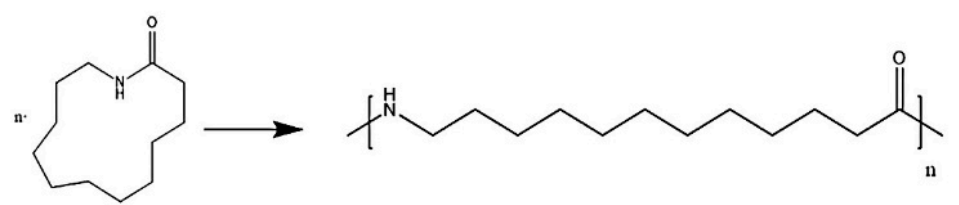

Figure 1. Reaction equations for the polymerization of polyamide $6(\mathbf{a})$, polyamide $6.6(\mathbf{b})$, and polyamide 12 (c).

For the three polyamide types, relevant marker compounds were identified, as summarized in Table 1. Structures are given in Tables S1-S3 in the electronic supplementary materials. Chromatographic separation of marker molecules of PA 6 and PA 6.6 were only 
achieved by using a HILIC column. Several problems occurred using an RP column such as co-eluting peaks and peak tailing. Different HILIC columns were tested, using either diol, ethylene bridged hybrid (BEH) amide, or zwitterionic materials as packaging. Best results were obtained using the BEH amide HILIC column. Throughout all measurements, default values of the ESI ion source were used due to sufficient signal intensities of the marker molecules.

Table 1. Summary of identified marker compounds for the three polyamide grades.

\begin{tabular}{|c|c|c|c|c|c|}
\hline $\begin{array}{l}\text { Polyamide } \\
\text { Type }\end{array}$ & Name & $\begin{array}{l}\text { Chemical } \\
\text { Formula }\end{array}$ & $\begin{array}{c}\text { Theoretical } \\
\mathrm{m} / \mathrm{z}\end{array}$ & $\begin{array}{l}\text { Experimental } \\
\mathrm{m} / \mathrm{z}\end{array}$ & $\begin{array}{l}\text { Retention } \\
\text { Time/min }\end{array}$ \\
\hline \multirow{6}{*}{ PA 6} & $\begin{array}{l}\varepsilon \text {-caprolactam, } \\
\text { Azepan-2-one }\end{array}$ & $\mathrm{C}_{6} \mathrm{H}_{11} \mathrm{NO}$ & 114.0919 & 114.0907 & 1.723 \\
\hline & $\begin{array}{c}\text { caprolactam cyclic dimer, } \\
\text { 1,8-Diazacyclotetra-decane-2,9-dione }\end{array}$ & $\mathrm{C}_{12} \mathrm{H}_{22} \mathrm{~N}_{2} \mathrm{O}_{2}$ & 227.1760 & 227.1773 & 2.119 \\
\hline & $\begin{array}{c}\text { caprolactam cyclic trimer, } \\
\text { 1,8,15-Triazacyclo-heneicosane-2,9,16-trione }\end{array}$ & $\mathrm{C}_{18} \mathrm{H}_{33} \mathrm{~N}_{3} \mathrm{O}_{3}$ & 340.2600 & 340.2591 & 2.326 \\
\hline & $\begin{array}{c}\text { caprolactam cyclic tetramer, } \\
\text { 1,8,15,22-Tetraazacyclo-octacosane-2,9,16,23-tetrone }\end{array}$ & $\mathrm{C}_{24} \mathrm{H}_{44} \mathrm{~N}_{4} \mathrm{O}_{4}$ & 453.3441 & 453.3452 & 2.552 \\
\hline & $\begin{array}{c}\text { caprolactam cyclic pentamer, } \\
1,8,15,22,29 \text {-Pentaazacyclopenta-triacontane- } \\
2,9,16,23,30 \text {-pentone }\end{array}$ & $\mathrm{C}_{30} \mathrm{H}_{55} \mathrm{~N}_{5} \mathrm{O}_{5}$ & 566.3890 & 566.4271 & 3.098 \\
\hline & $\begin{array}{c}\text { caprolactam cyclic hexamer, } \\
1,8,15,22,29,36- \\
\text { Hexaazacyclodotetracontane- } 2,9,16,23,30,37 \text {-hexone }\end{array}$ & $\mathrm{C}_{36} \mathrm{H}_{66} \mathrm{~N}_{6} \mathrm{O}_{6}$ & 679.4339 & 679.5105 & 3.606 \\
\hline \multirow{3}{*}{ PA 6.6} & 1,7-Diazacyclotetra-decane-8,14-dione & $\mathrm{C}_{12} \mathrm{H}_{22} \mathrm{~N}_{2} \mathrm{O}_{2}$ & 227.1760 & 227.1770 & 2.119 \\
\hline & 1,7,15,21-Tetraazacyclo-octacosane-8,14,22,28-tetrone & $\mathrm{C}_{24} \mathrm{H}_{44} \mathrm{~N}_{4} \mathrm{O}_{4}$ & 453.3441 & 453.3449 & 2.683 \\
\hline & $\begin{array}{l}1,7,15,21,29,35- \\
\text { Hexaazacyclodotetracontane- } 8,14,22,28,36,42 \text {-hexone }\end{array}$ & $\mathrm{C}_{36} \mathrm{H}_{66} \mathrm{~N}_{6} \mathrm{O}_{6}$ & 679.4339 & 679.5112 & 3.324 \\
\hline \multirow{3}{*}{ PA 12} & $\begin{array}{c}\text { laurolactam, } \\
\text { Azacyclcotridecane-2-one }\end{array}$ & $\mathrm{C}_{12} \mathrm{H}_{23} \mathrm{NO}$ & 198.1858 & 198.1860 & 1.440 \\
\hline & 1,14-diazacyclohexacosane-2,15-dione & $\mathrm{C}_{24} \mathrm{H}_{46} \mathrm{~N}_{2} \mathrm{O}_{2}$ & 395.3638 & 395.3635 & 1.403 \\
\hline & 1,14,27-triazacyclononatriacontane-2,15,28-trione & $\mathrm{C}_{36} \mathrm{H}_{69} \mathrm{~N}_{3} \mathrm{O}_{3}$ & 592.5417 & 592.5404 & 1.365 \\
\hline
\end{tabular}

These marker compounds can be used for the identification of the different polyamide grades if these are individually present in the recyclate. In case of mixtures of PAs, the cyclic trimer and cyclic pentamer are selective markers for PA 6. Therefore, the presence or absence of the corresponding peaks in the chromatogram are an unequivocal evidence for the presence or absence of PA 6 in a recyclate. However, for a mixture of PA 6 and PA 6.6 the proof for the presence of PA 6.6 becomes much less straightforward. The marker compounds identified for PA 6.6 are isomers of the cyclic dimer/tetramer/hexamer of PA 6 (see Table 2), so that a chromatographic separation is difficult and a mass spectrometric differentiation is hampered due to the same exact masses. A way around this problem may be the use of the ratio between the total peak area of the two coeluting tetramers (resulting from both PA 6 and PA 6.6) and the peak area of the trimer (resulting from PA 6). However, this approach becomes unreliable when one PA is present in a large excess over the other one. 
Table 2. Structures of the identified cyclic marker compounds for PA 6 and PA 6.6 having the identical exact mass.

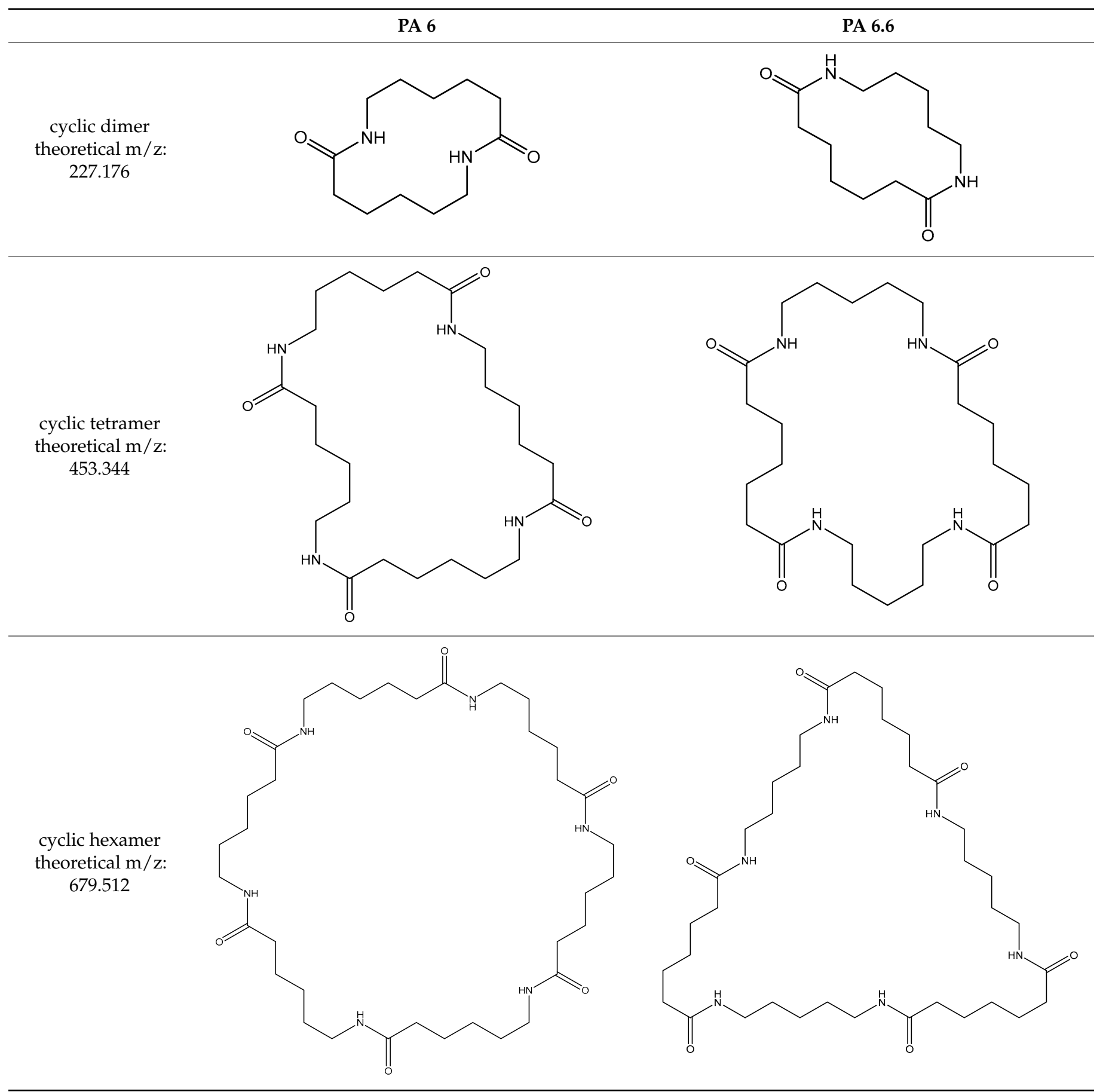

A thorough optimization of the chromatographic separation was done by an adaption of the gradient elution using a higher amount of salt, leading to the final conditions mentioned in Section 2.2. A chromatogram of a mixture of PA 6, PA 6.6, and PA 12 can be seen in Figure 2. The cyclic compounds related to PA 12 (peaks 1-3) elute shortly after the injection peak and cannot be separated by a HILIC column. The cyclic dimer of PA 6 and PA 6.6 coelute (peak 4), and their cyclic tetramers lead to a peak with a shoulder (peak 6). The best that could be achieved was a partial peak separation of the two cyclic hexamers of PA 6 and PA 6.6 with a calculated resolution close to 1 (peaks 8 and 9). However, even this resolution may be too poor when the two compounds are present at quite different 
levels. Thus, the two often used identification features, exact mass and retention time, are not fully feasible for distinguishing the polyamide grades 6 and 6.6.

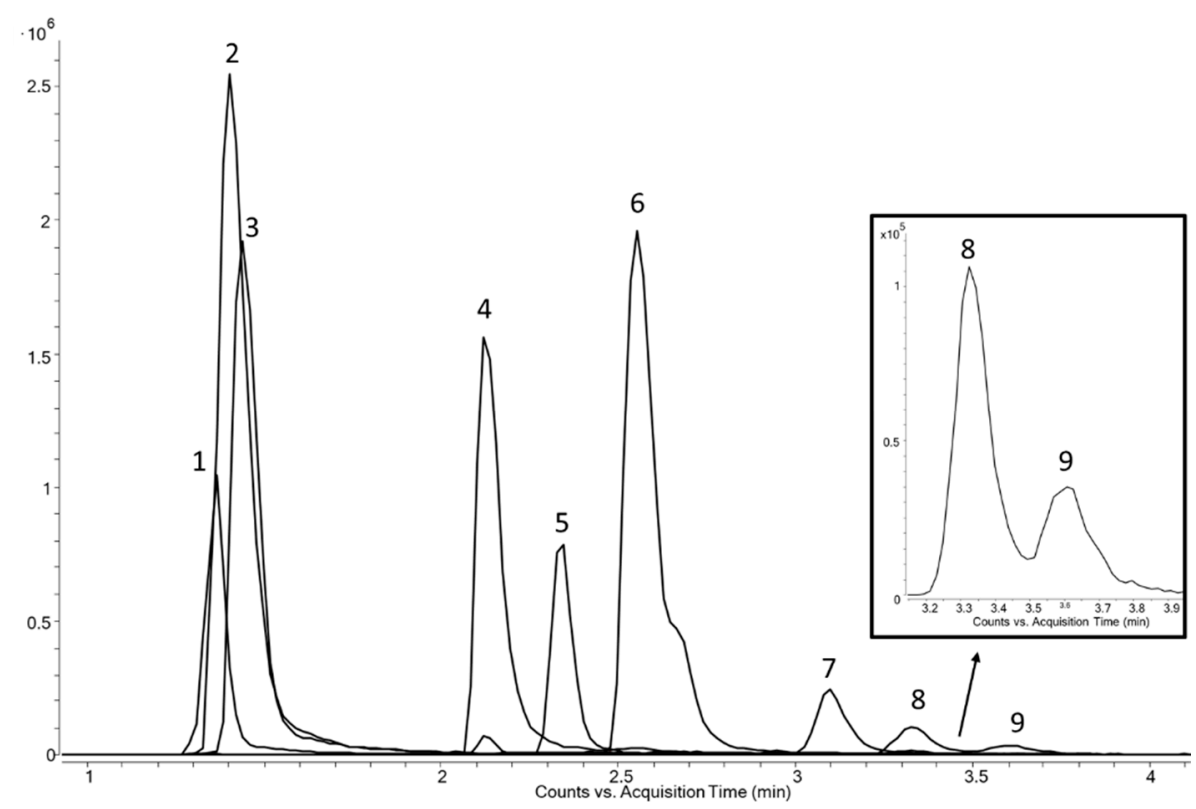

Figure 2. Extracted ion chromatogram of PA 6, PA 6.6, and PA 12. Peaks: 1 = cyclic trimer of PA 12; $2=$ cyclic dimer of PA 12;3 = cyclic monomer of PA 12; $4=$ cyclic dimers of PA 6/6.6; $5=$ cyclic trimer of PA $6 ; 6=$ cyclic tetramers of PA 6/6.6; $7=$ cyclic pentamer of PA 6; $8=$ cyclic hexamer of PA 6.6; and $9=$ cyclic hexamer of PA 6 .

Another possibility for the differentiation of compounds are mass spectrometric fragmentation patterns and the use of characteristic fragmentation products. A comparison of the MS/MS spectra of the cyclic hexamers of polyamide 6 and 6.6, recorded with a collision energy of $40 \mathrm{~V}$ can be seen in Figure 3. Most signals are identical; the main difference which can be found is the fragment with a m/z of 114.09 only visible in PA 6, which corresponds to $\varepsilon$-caprolactam. However, there is no specific fragment for PA 6.6 and therefore a differentiation of these two polyamide grades is not possible.

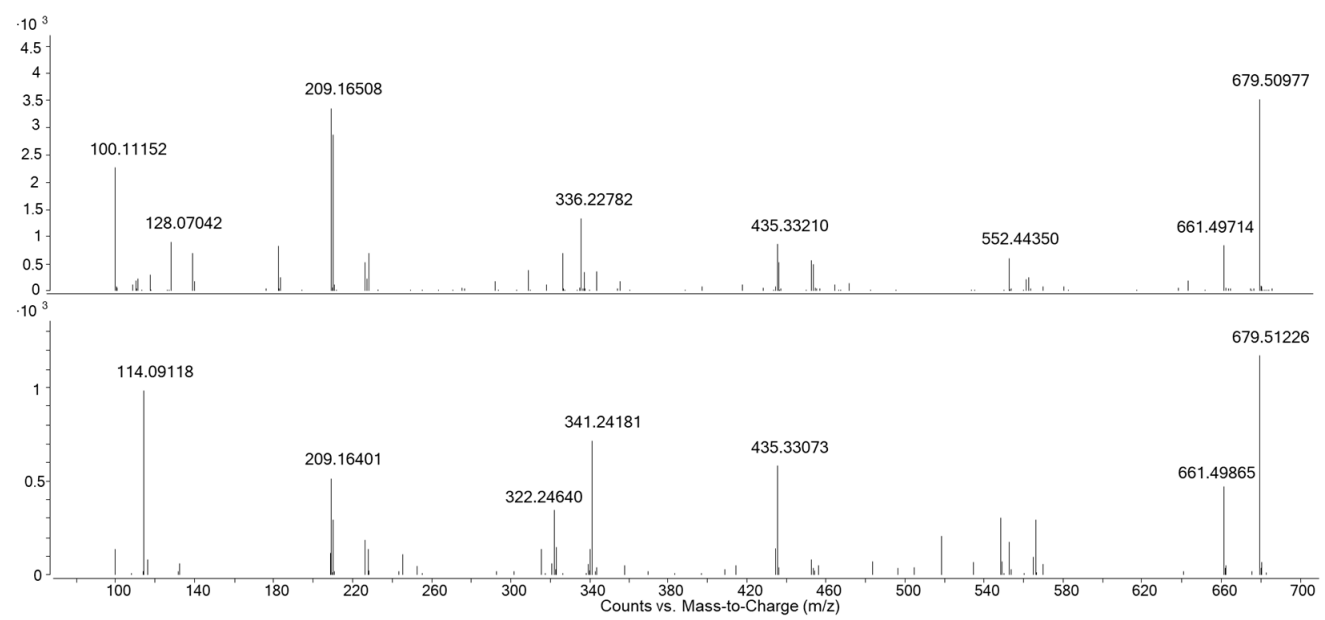

Figure 3. MS/MS data of the cyclic hexamer of PA 6.6 (top) and PA 6 (bottom), recorded with a collision energy of $40 \mathrm{~V}$.

Therefore, an alternative unique parameter is desirable for the clear identification of these marker compounds. This can be accomplished by introducing a further dimension of separation through the use of ion mobility in the mass spectrometer, whereby the ionized 
molecules are separated in the gas phase according to their shape and charge. Bigger molecules travel longer through the drift-tube, caused by more collisions with the drift gas compared with smaller ones. The intention of using ion mobility was the idea that the cyclic isomeric compounds are folded differently, dependent on the location of the functional groups. The results of the IM-measurements are presented in Table 3.

Table 3. Results of the IM-QTOF measurements for the different marker compounds of the polyamide grades.

\begin{tabular}{ccccc}
\hline $\mathbf{m} / \mathbf{z}$ & $\begin{array}{c}\text { Polyamide } \\
\text { Grade }\end{array}$ & $\begin{array}{c}\text { Retention } \\
\text { Time/min }\end{array}$ & Drift Time/ms & DT $_{\mathbf{C C S}} \mathbf{N}_{\mathbf{2}} / \mathbf{A}^{2}$ \\
\hline $\begin{array}{c}227.1760 \\
\text { (cyclic dimer) }\end{array}$ & 6 & 2.13 & 19.87 & 150.4 \\
\hline $\begin{array}{c}340.260 \\
\text { (cyclic trimer) }\end{array}$ & 6.6 & 2.13 & 20.83 & 157.8 \\
\hline $\begin{array}{c}453.3441 \\
\text { (cyclic tetramer) }\end{array}$ & 6 & 2.34 & 23.93 & 178.8 \\
\hline $\begin{array}{c}566.3890 \\
\text { (cyclic pentamer) }\end{array}$ & 6 & 2.56 & 28.35 & 209.6 \\
\hline $\begin{array}{c}679.4339 \\
\text { (cyclic hexamer) }\end{array}$ & 6 & 2.56 & 29.49 & 214.7 \\
\hline 198.1858 & 6.6 & 3.10 & 31.47 & 231.5 \\
\hline 395.3638 & 12 & 3.61 & 34.79 & 255.1 \\
\hline 592.5417 & 12 & 1.45 & 35.67 & 148.5 \\
\hline
\end{tabular}

It can be seen that the retention times of the marker compounds of PA 12 are rather low, due to their low polarity and they elute simultaneously. However, through the collision cross section, a clear parameter is given for an easy differentiation. In the case of PA 6 and PA 6.6, all compounds with the identical mass have the same retention time (except for the cyclic hexamer), yet drift times and therefore the ${ }^{\mathrm{DT}} \mathrm{CCS}_{\mathrm{N} 2}$ are different. The difference of the CCS value increases with increasing mass of the oligomer, indicating that the idea of different folding being dependent on the position of the functional groups is valid. Limitations of this approach can be seen with the smaller molecules. Here, the resolution of the drift-tube is not sufficient for a peak separation in the drift spectra. Future advances in the drift-tube ion-mobility technology can be expected to lead to further improvements in this field. Another possibility to enhance resolution is the use of recently developed, sophisticated software packages for high-resolution demultiplexing which significantly increase the resolution power [32] but have not yet been available for this work.

Best suited for the qualitative differentiation of PA 6 and PA 6.6 is the cyclic hexamer, because a separation by chromatography is partly possible and the additional CCS value guarantees a clear distinction, as depicted in Figure 4.

It can be seen that when measuring a mixture of PA 6 and PA 6.6, the drift sprectrum shows at the exact mass of the cyclic hexamer (m/z: 679.5107) not a single peak but a split peak. This means that at this specific mass not only is one ionized molecule species present but two, which possess two different drift times. This can be used to extract a specific drift time to differentiate the two peaks in the chromatogram.

If the chromatogram is extracted over the whole drift time of 33.1-36.8 ms, the double peak of the cyclic hexamer is observed. However, if only one of the drift times, either from $35.0-36.8 \mathrm{~ms}$ or from $33.08-35.0 \mathrm{~ms}$ is selected, one specific hexamer is extracted selectively. At the higher drift time, the hexamer of PA 6.6 is visible and at the lower one, the hexamer of PA 6. Therefore, dependent on the drift time, or the resulting CCS-value, polyamide 6 and 6.6 can be distinguished. This qualitative approach is feasible down to a concentration of $0.2 \mathrm{wt} \%$ polyamide contamination in polyolefin recyclates. 


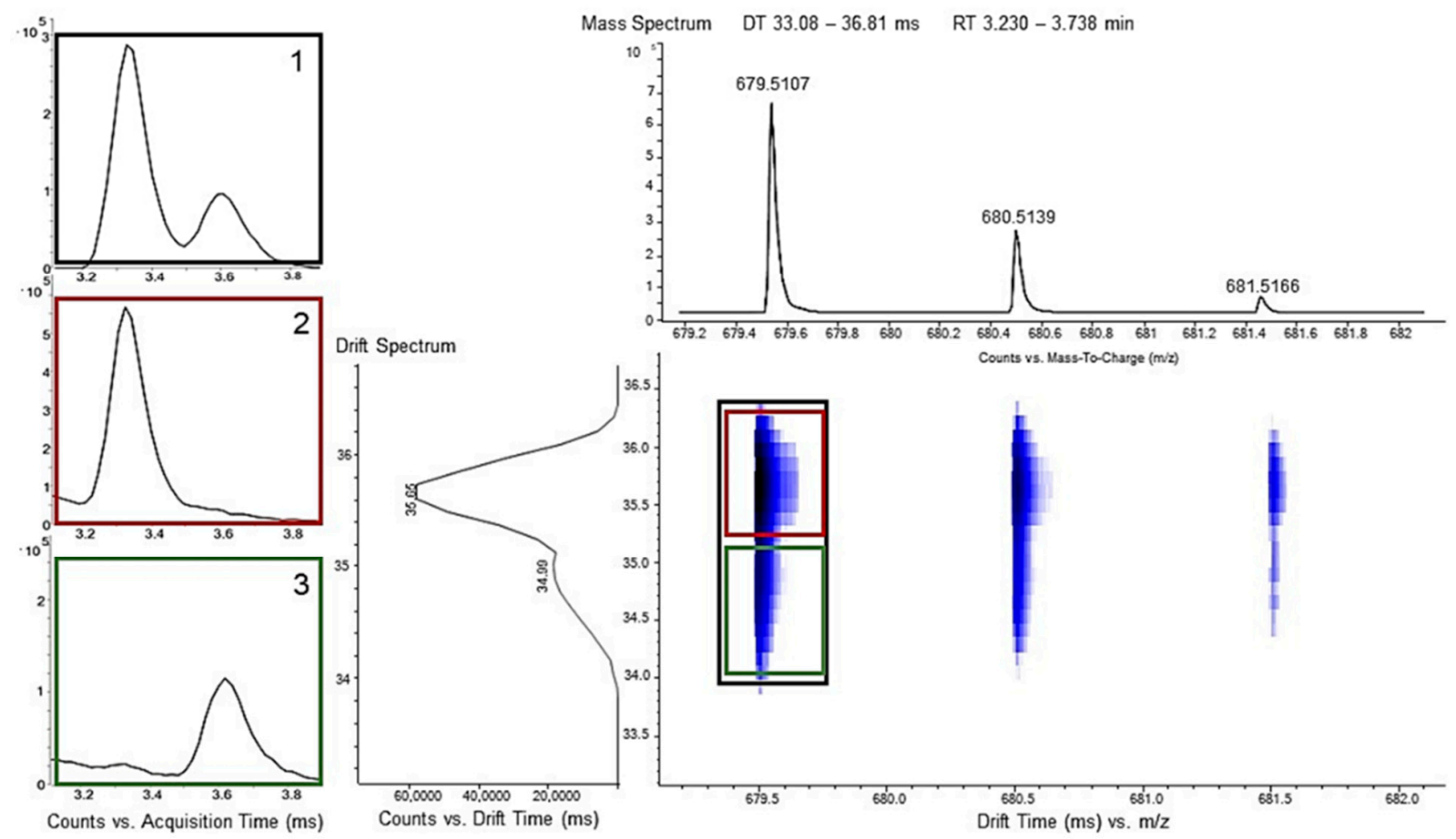

Figure 4. MS and DTIM data for the cyclic hexamer of a mixture of PA 6 and 6.6. At the exact mass of 679.511, a double peak in the drift spectrum can be observed, originating from the two different marker molecules, which vary only in the positioning of the functional groups. Extracted ion chromatogram of 1: drift time window of 33.1-36.8 ms, 2: drift time window of 35.0-36.8 ms, and 3: drift time window of 33.08-35.0 ms.

\section{Conclusions}

In this study, a method for the qualitative differentiation of polyamide 6, 6.6, and 12 was presented by the usage of ion-mobility as an additional separation step. All found marker compounds were characterized by means of determination of the exact mass, fragmentation pattern, retention time, and CCS value. Therefore, it can be guaranteed that these compounds can be differentiated from one another and hence are applicable for the differentiation of polyamide grades. This method is not only applicable if one of these polyamides is present but as well for mixtures. By using ion-mobility, a differentiation of polyamide 6 and 6.6 was achieved by comparison of the resulting CCS values.

Supplementary Materials: The following are available online at https:/ / www.mdpi.com/article/ 10.3390/polym13122032/s1, Table S1: Structures of the cyclic compounds of PA 12, Table S2: Structures of the cyclic compounds of PA 6, Table S3: Structures of the cyclic compounds of PA 6.6.

Author Contributions: Conceptualization, A.S.; funding acquisition, J.F.; investigation, A.S.; methodology, A.S.; supervision, W.B.; visualization, A.S.; writing-original draft, A.S.; and writing-review \& editing, W.B. All authors have read and agreed to the published version of the manuscript.

Funding: This research received no external funding.

Institutional Review Board Statement: Not applicable.

Informed Consent Statement: Not applicable.

Data Availability Statement: The data presented in this study are available on request from the corresponding author.

Acknowledgments: Open Access Funding by the University of Linz.

Conflicts of Interest: The authors declare no conflict of interest. 


\section{References}

1. Eurostat. Generation of Waste by Waste Category. Available online: https:/ / ec.europa.eu/eurostat/databrowser/view/ENV_ WASGEN_custom_605013/default/table?lang=en (accessed on 24 February 2021).

2. European Commision. Living Well, Within the Limits of Our Planet: General Union Environment Action Programme to 2020; Publication Office of the European Union: Luxembourg, 2014.

3. Directive (EU) 2018/852 of the European Parliament and of the Council of 30 May 2018 Amending Directive 94/62/EC on Packaging and Packaging Waste: L 150/141; Official Journal of the European Union: Luxenbourg, 2018.

4. Vilaplana, F.; Karlsson, S. Quality Concepts for the Improved Use of Recycled Polymeric Materials: A Review. Macromol. Mater. Eng. 2008, 293, 274-297. [CrossRef]

5. Karlsson, S. Recycled Polyolefins. Material Properties and Means for Quality Determination. In Long Term Properties of Polyolefins; Albertsson, A.-C., Ed.; Springer: Berlin/Heidelberg, Germany, 2004; pp. 201-230. ISBN 978-3-540-40769-0.

6. Plastics Europe. Plastics-the Facts. 2020. Available online: https://www.plasticseurope.org/en/resources/publications/4312 - plastics-facts-2020 (accessed on 23 February 2021).

7. Pracella, M. Blends and Alloys. In Modification of Polymer Properties; Elsevier: Amsterdam, The Netherlands, 2017; pp. 155-184. ISBN 9780323443531.

8. Feldman, D. Polyblend Compatibilization. J. Macromol. Sci. Part A 2005, 42, 587-605. [CrossRef]

9. Van Velzen, E.U.T.; Chu, S.; Chacon, F.A.; Brouwer, M.T.; Molenveld, K. The impact of impurities on the mechanical properties of recycled polyethylene. Packag. Technol. Sci. 2021, 34, 219-228. [CrossRef]

10. White, J.M.; Yang, J. Miscibility and Characteristics of Polyolefin Blends. In Polyolefin Blends; John Wiley \& Sons, Inc.: Hoboken, NJ, USA, 2007; pp. 27-65. ISBN 9780471790587.

11. Faraca, G.; Astrup, T. Plastic waste from recycling centres: Characterisation and evaluation of plastic recyclability. Waste Manag. 2019, 95, 388-398. [CrossRef] [PubMed]

12. Hu, B.; Serranti, S.; Fraunholcz, N.; Di Maio, F.; Bonifazi, G. Recycling-oriented characterization of polyolefin packaging waste. Waste Manag. 2013, 33, 574-584. [CrossRef] [PubMed]

13. Eriksen, M.K.; Damgaard, A.; Boldrin, A.; Astrup, T.F. Quality Assessment and Circularity Potential of Recovery Systems for Household Plastic Waste. J. Indust. Ecol. 2019, 23, 156-168. [CrossRef]

14. Ragaert, K.; Delva, L.; van Geem, K. Mechanical and chemical recycling of solid plastic waste. Waste Manag. 2017, 69, 24-58. [CrossRef] [PubMed]

15. Kaiser, K.; Schmid, M.; Schlummer, M. Recycling of Polymer-Based Multilayer Packaging: A Review. Recycling $2018,3,1$. [CrossRef]

16. Ebnesajjad, S. Plastic Films in Food Packaging: Materials, Technology, and Applications; William Andrew: Oxford, UK, 2013; ISBN 978-1-4557-3112-1.

17. Marchildon, K. Polyamides-Still Strong After Seventy Years. Macromol. React. Eng. 2011, 5, 22-54. [CrossRef]

18. Herzog, B.; Kohan, M.I.; Mestemacher, S.A.; Pagilagan, R.U.; Redmond, K.; Sarbandi, R. Polyamides. In Ullmann's Encyclopedia of Industrial Chemistry; Wiley-VCH: Weinheim, Germany, 2000; pp. 1-47. ISBN 9783527303854.

19. Stangenberg, F.; Agren, S.; Karlsson, S. Quality Assessments of Recycled Plastics by Spectroscopy and Chromatography. Chromatographia 2004, 59, 101-106.

20. Gaymans, R. Polyamides. In Synthetic Methods in Step-Growth Polymers; John Wiley \& Sons, Inc.: Hoboken, NJ, USA, 2003; pp. 135-195, ISBN 0-471-38769-X.

21. Gall, M.; Schweighuber, A.; Buchberger, W.; Lang, R. Plastic Bottle Cap Recycling-Characterization of Recyclate Composition and Opportunities for Design for Circularity. Sustainability 2020, 12, 378. [CrossRef]

22. Žagar, E.; Češarek, U.; Drinčić, A.; Sitar, S.; Shlyapnikov, I.M.; Pahovnik, D. Quantitative Determination of PA6 and/or PA66 Content in Polyamide-Containing Wastes. ACS Sustain. Chem. Eng. 2020, 8, 11818-11826. [CrossRef]

23. Gramshaw, J.W.; Soto-Valdez, H. Migration from polyamide 'microwave and roasting bags' into roast chicken. Food Addit. Contam. 1998, 15, 329-335. [CrossRef] [PubMed]

24. Guaita, C. HPLC analysis of cyclo-oligoamides 6 and 66. Makromol. Chem. 1984, 185, 459-465. [CrossRef]

25. Heimrich, M.; Bönsch, M.; Nickl, H.; Simat, T.J. Cyclic oligomers in polyamide for food contact material: Quantification by HPLC-CLND and single-substance calibration. Food Addit. Contam. Part A 2012, 29, 846-860. [CrossRef]

26. Heimrich, M.; Nickl, H.; Bönsch, M.; Simat, T.J. Migration of Cyclic Monomer and Oligomers from Polyamide 6 and 66 Food Contact Materials into Food and Food Simulants: Direct Food Contact. Packag. Technol. Sci. 2015, 28, 123-139. [CrossRef]

27. Hoppe, M.; de Voogt, P.; Franz, R. Identification and quantification of oligomers as potential migrants in plastics food contact materials with a focus in polycondensates-A review. Trends Food Sci. Technol. 2016, 50, 118-130. [CrossRef]

28. Jenke, D.; Poss, M.; Sadain, S.; Story, J.; Smith, W.; Reiber, D. Identification of caprolactam oligomers and related compounds in aqueous extracts of nylon-6. J. Appl. Polym. Sci. 2005, 95, 1262-1274. [CrossRef]

29. Kappenstein, O.; Ebner, I.; Förster, C.; Richter, S.; Weyer, J.; Pfaff, K.; Luch, A. Validation and application of an LC-MS/MS method for the determination of cyclic oligomers originating from polyamide 6 and polyamide 66 in food simulant. Food Addit. Contam. Part A 2018, 35, 1410-1420. [CrossRef]

30. Abe, Y.; Mutsuga, M.; Ohno, H.; Kawamura, Y.; Akiyama, H. Isolation and Quantification of Polyamide Cyclic Oligomers in Kitchen Utensils and Their Migration into Various Food Simulants. PLoS ONE 2016, 11, 1-15. [CrossRef] 
31. Schweighuber, A.; Gall, M.; Fischer, J.; Liu, Y.; Braun, H.; Buchberger, W. Development of an LC-MS method for the semiquantitative determination of polyamide 6 contaminations in polyolefin recyclates. Anal. Bioanal. Cchem. 2021, 413, 1091-1098. [CrossRef] [PubMed]

32. May, J.C.; Knochenmuss, R.; Fjeldsted, J.C.; McLean, J.A. Resolution of Isomeric Mixtures in Ion Mobility Using a Combined Demultiplexing and Peak Deconvolution Technique. Anal. Chem. 2020, 92, 9482-9492. [CrossRef] [PubMed] 